\title{
Leverage decision and manager compensation with choice of effort and volatility
}

\author{
Abel Cadenillas ${ }^{\mathrm{a}}$, Jakša Cvitanićb ${ }^{\text {, Fernando Zapatero }}{ }^{\mathrm{c}}$ \\ ${ }^{a}$ University of Alberta, Department of Mathematical and Statistical Sciences, Edmonton, \\ Alberta, Canada \\ ${ }^{\mathrm{b}}$ USC, Departments of Mathematics and Economics, Los Angeles, CA 90089, USA \\ ${ }^{\mathrm{c}}$ USC, Marshall School of Business, FBE, Los Angeles, CA 90089, USA
}

(Received 10 October 2002; accepted: 16 June 2003)

\begin{abstract}
We study the incentive effects of granting levered or unlevered stock to a risk-averse manager. The stock is granted by risk-neutral shareholders who choose leverage and compensation level. The manager applies costly effort and selects the level of volatility, both of which affect expected return. The results are driven by the attempt of the risk-neutral shareholders to maximize the value of their claims net of the compensation package. We consider a dynamic setting and find that levered stock is optimal for high-type managers, firms with high momentum, large firms, and firms for which additional volatility only implies a modest increase in expected return.
\end{abstract}

JEL Classification: C61, G39

Keywords: Capital structure, principal-agent, stochastic control

The research of A. Cadenillas was supported by the Social Sciences and Humanities Research Council of Canada grant 410-2000-0631. The research of J. Cvitanic was supported in part by the National Science Foundation, under Grant NSF-DMS-00-99549. This paper is based on a previous paper titled "Executive Stock Options with Effort Disutility and Choice of Volatility." We are especially grateful to Kevin Murphy for many detailed comments on that paper. We also thank Héctor Chade, Li Jin, Fulvio Ortu, Rafael Repullo, Manuel Santos, Luigi Zingales, and seminar participants at HEC (Montreal), NYU, McGill, USC, Princeton, Wharton, BI (Oslo), Copenhagen School of Business, California Institute of Technology, Florida International University, CEMFI, ASU, Humboldt Universität zu Berlin, the Winter 2000 Meeting of the Canadian Mathematical Society, the 2001 Canada-China Math Congress, and the Second World Congress of the Bachelier Finance Society (2002) for comments. Last, but not least, many comments and suggestions of an anonymous referee (including a key note with regard to the focus of the paper) are gratefully acknowledged. Existing errors are our sole responsibility. 


\section{Introduction}

Modigliani and Miller (1958) establish that if the firm's investment policy is fixed and if there are no taxes and contracting costs, then the firm's value is independent of its capital structure. Since that seminal result, financial economists have relaxed some of these assumptions to analyze optimal capital structure. For example, Modigliani and Miller (1963) show that because debt provides the firm a tax shield, it may be of benefit for firms to issue debt. However, debt may also induce some costs, for example bankruptcy costs (Kraus and Litzenberger, 1973) or agency costs (Jensen and Meckling, 1976). By balancing such costs and benefits, one should then be able to determine optimal capital structure.

While Modigliani and Miller apply their arguments to financing policy, their result generally applies to all firm policies. In this paper, we examine the joint determination of compensation and leverage decisions in a dynamic framework, notably, we analyze the impact of the choice of effort and volatility on the value of the firm. We ignore taxes and bankruptcy costs to keep the analysis simple. We emphasize that because we use a dynamic setting our conclusions depend directly on the ability of the manager to adjust the level of effort in a state contingent way.

The specific problem we consider is as follows. A risk-averse manager whose compensation consists exclusively of (possibly) levered stock has to choose optimal levels of effort and volatility. Effort is costly, unlike volatility. The manager's compensation is determined by existing risk-neutral shareholders, where existing shareholders are outside investors who decide how many shares of stock to give to the manager and how much debt to issue. Both of these shareholder decisions are interlaced: the objective of the risk-neutral shareholders is to maximize the expected value of the firm (net of the value of the compensation package) by selecting the levels of compensation and leverage that will provide optimal incentives to the manager. Our setting sheds light on the factors that determine some of the leverage ratios observed in practice.

Our main conclusions are the following. The optimal policy is to grant stock with high leverage to "good" managers (those who are more efficient in affecting firm value through effort) and stock with low leverage to "bad" managers. The momentum of the firm's value has the same effect, high momentum is equivalent to a high-type manager. Also, low leverage seems to be preferable for firms for which extra volatility translates into very high expected return. The former result is obviously difficult to test (a distinction between good and bad managers has to be established). The latter result seems to be consistent with the empirical findings of Smith and Watts (1992) who find that leverage tends to be lower in firms with good growth prospects. Finally, optimal leverage will be lower for smaller companies than large companies. Overall, our model is in the spirit of the results of Lewellen (2002), which finds empirical evidence of the interaction between risk-aversion of the managers and financing decisions. Our model is also complementary to the results of Morellec (2003), who presents a comprehensive model with taxes, possible default, and agency problems, and concludes that optimal 
leverage tends to be low, as observed in practice. We also mention here the work of Bertrand and Schoar (2002), who document that manager characteristics help explain the financing decision, the premise of this paper.

Obviously, our paper is related to the executive compensation literature (see Murphy, 1999, for an extensive review) and the incentive effects of different types of compensation packages, as studied in Jensen and Murphy (1990). Given the option-like features of levered stock, our paper complements the literature on executive stock options and their incentive effects. In particular, the choice of an optimal strike price in Hall and Murphy $(2000,2002)$ is a problem similar to the choice of optimal leverage that we consider in this paper.

On the technical side, our paper is related to the growing literature on dynamic principal-agent models. This literature started with Holmstrom and Milgrom (1987) and includes Schättler and Sung (1993), Sung (1995), Bolton and Harris (2001), and Ou-Yang (2003). Carpenter (2000) also considers a dynamic setting.

The paper is structured as follows. In Section 2 we describe the dynamics of firm value and the effects of the manager's actions on those dynamics. We also characterize the objectives of the two players in our model: the manager and the firm. In Section 3 we derive the optimal effort and volatility choices of the manager, as well as the optimal number of shares and leverage to be chosen by the firm. In Section 4 we present some numerical examples and derive the main economic results of the paper. We close this work with some conclusions.

\section{The setting}

We consider the problem of a risk-neutral shareholder who wants to maximize the value of its claims net of the compensation package of the firm's manager. As in Stulz (1990) and Morellec and Smith (2003), we assume that shareholders have decision rights over financing and compensation policy. We consider a dynamic setting. As we will see below, the economic results we derive are essentially dynamic and do not obtain in the equivalent static setting. We discuss the static setting and its solution at the end of the next section.

\subsection{Firm value and stock}

Following Black and Scholes (1973) and Merton (1974), the literature on compensation policy and capital structure decisions typically assumes that the value of unlevered assets is governed by a geometric Brownian motion

$$
\frac{d V_{t}}{V_{t}}=\mu d t+\sigma d W_{t}
$$

with starting value $V_{0}$. The process $\left(W_{t}\right)_{t \geq 0}$ is a standard Brownian motion process and $\mu$ and $\sigma$ are constant parameters. In our framework, the manager can affect both 
the growth rate and volatility of this value process. In particular, we assume that $\left(V_{t}\right)_{t \geq 0}$ satisfies

$$
d V_{t}=\mu V_{t} d t+\delta u_{t} d t+\alpha v_{t} V_{t} d t+v_{t} V_{t} d W_{t}
$$

where $u$ and $v$ are adapted stochastic processes chosen by the manager, $\delta \in[0, \infty)$ and $\alpha \in(0, \infty)$. We assume that $E\left[\int_{0}^{T}\left|u_{t}\right|^{2} d t\right]<\infty$ and $E\left[\int_{0}^{T}\left|v_{t} V_{t}\right|^{2} d t\right]<\infty$, where $T$ is the horizon of the manager, as described later. The constant parameter $\mu$ is exogenous, and we interpret it as the momentum of the firm's value, which the manager of the firm cannot affect. In an equilibrium setting, this parameter would have to be related to the interest rate prevailing in the economy. The control $u$ is the level of effort the manager expends in running the company. The higher the effort $u$, the higher the expected value of the firm. We will assume later that the manager's effort is costly. On the other hand, the choice of $v$ is equivalent to the choice of the firm's volatility, although it also has an impact on the expected value. We interpret the choice of $v$ as a choice of projects, such that the manager selects a project or strategy from a set characterized by different levels of risk. The parameter $\alpha$ is a measure of the benefits associated with taking more risk, and is a characteristic of the firm. One possible interpretation of $\alpha$ (and, potentially, a way to estimate it empirically) is that it is the slope of the equivalent of the Capital Market Line which results from all the projects available to the firm (more about the distinction between firm-specific and market risk can be found below). Arguably, $\alpha$ will be high for those companies with relatively better growth prospects, such as new companies. This interpretation will be important when we compare our results with the empirical observations of Smith and Watts (1992). The parameter $\delta$ is a measure of the impact of the manager's effort on the value of the firm, and can be interpreted as an indicator of the type (quality) of the manager. Carpenter (2000) studies the optimal choice of $v$ for the case in which $\delta=0$.

We emphasize that this is a partial equilibrium setting. We do not compare the dynamics of the value of our firm with the dynamics of other firms. If all the investors had perfect information, the value of our firm would be decided in equilibrium and the manager would not be able to influence the drift independent of the volatility; i.e., $\delta$ would be equal to zero.

As discussed earlier, shareholders can issue debt. We denote by $B$ the face value of the debt. At maturity of the debt, the value of the stock, i.e., the residual claim, is

$$
S=(V-B)^{+} .
$$

In this paper we only consider one source of uncertainty, a single Brownian motion process $W$. It would be more realistic to distinguish between idiosyncratic and systematic risk, and in our setting, we could do that by including in the dynamics of $V$ a second Brownian motion process that is independent of the first one. The diffusion term of the dynamics of the firm's value would be of the type $v V d W_{1}+\sigma V d W_{2}$, where the process $W_{1}$ would describe the idiosyncratic risk, while $W_{2}$ would represent 
the systematic or market risk. The manager would choose $v$ as above, while $\sigma$ would be exogenous. However, to make this a complete-markets setting (as is needed for technical reasons), we should allow the manager to trade in a security that depends on $W_{2}$. This is realistic because managers cannot sell the stock of the company until it is vested, but they are allowed to trade in other securities. In particular, as shown by Jin (2002), managers can diversify the market risk component of the underlying stock by trading (a portfolio that replicates) the market index. As Jin (2002) shows, the market risk becomes irrelevant. Hence, the model we study in this paper can be considered a reduced form of the model described here. Our specific setting is tractable and considers the relevant risk component.

\subsection{The manager}

The manager is risk averse and exerts costly effort. We assume that the manager receives stock as the only source of compensation. In our model, the manager chooses $u$ and $v$ to maximize expected utility. The objective of the manager is

$$
\max _{u, v} E\left[\log \left\{n\left(V_{T}-B\right)^{+}\right\}-\frac{1}{2} \int_{0}^{T} u_{t}^{2} d t\right] .
$$

In (4), $n$ is the number of shares of stock the manager receives as compensation, and $B=0$ corresponds to an unlevered firm. The second term of the objective function represents the cost of effort, which might be, for example, the result of spending more time working for the firm. We assume that the cost of effort is an increasing, convex function, with quadratic cost being a convenient approximation. The horizon of the manager is $T$, and is determined by the vesting period, the maturity of the debt, and the time the manager plans to stay with the company. In order to simplify the problem, we collapse all those variables into the single constant parameter $T$. The manager will optimally choose a non-negative level of effort $u$. The other control, $v$, involves the choice of projects the firm will undertake and has no effect on the cost of the manager's effort since it does not require any effort. On the other hand, $v$ does affect the expected value of the compensation package, as the manager has a menu of projects and decides the level of risk to undertake. The projects are, in principle, comparable in quality since projects with higher risk also offer a higher expected return. By allowing the manager to choose the level of volatility we intend to address the problem of the potential incentives to increase volatility that the levered firm's options-like features might trigger. As discussed in Jensen and Meckling (1976), the manager that owns equity of the firm might prefer a higher level of volatility when the firm is levered than when it is unlevered. Similarly, John and John (1993) show that a risk-neutral manager that receives levered stock will have incentives to choose riskier projects. As we will see later, our results are different because in our model the manager is risk-averse and does not enjoy any perks from holding a management position. 
We do not introduce a weighting parameter that would measure the relative importance of the utility from the stock compensation versus the cost of effort. The reason is that this constant would be equivalent to the parameter $\delta$ that represents the type of the manager: a manager with high $\delta$ is equivalent to a manager that does not care much about the cost of effort.

Given logarithmic utility, the number of shares of stock $n$ becomes irrelevant for incentive purposes, although it is important to determine the total compensation of the manager and whether the compensation satisfies the manager's participation constraint (discussed later).

In the next section we discuss the solution to this problem. We also consider the equivalent static problem, in which the agent chooses ex ante a constant value for both $u$ and $v$, rather than treating them as functionals of $V$.

\subsection{The shareholders (outside investors)}

Shareholders (outside investors) compensate the manager with stock that becomes vested at time $T$. Shareholders choose both the number of shares of stock, $n$, to grant to the manager and the level of debt of the company, $B$. A debt level of zero indicates an unlevered firm. We assume that shareholders are risk-neutral and care about the final value of the company net of the cost of compensation. On the other hand, when choosing the compensation package and debt level, shareholders must guarantee that the utility of the manager is at least as great as a reservation utility $R$. This can be interpreted as the utility that the manager would achieve in the best alternative job offer from another firm. This restriction amounts to a participation constraint, which is standard in the principal-agent literature.

We require the level of debt, $B$, is no larger than the initial value of the firm, $V_{0}$. As we will argue later, in our setting, even if the nominal value of debt exceeds the value of the firm, at maturity the stock will have a positive value given the optimal effort of the manager. Since we are only interested in qualitative results, our conclusions do not depend on this. Let

$$
h(B, n)=\lambda E\left[V_{T}\right]-n E\left[\left(V_{T}-B\right)^{+}\right]
$$

and

$$
A(R)=\left\{(B, n) \in\left[0, V_{0}\right] \times[0, \infty): \max _{u, v} E\left[\log \left\{n\left(V_{T}-B\right)^{+}\right\}-\frac{1}{2} \int_{0}^{T} u_{t}^{2} d t\right] \geq R\right\} .
$$

The objective of the firm is then

$$
\max _{(B, n) \in A(R)} h(B, n),
$$

where $\lambda$ is an exogenous constant that represents the relative importance for the firm of the expected value of the stock with respect to the compensation package. For a 
given debt level $B$, the ratio $n / \lambda$ is an indicator of the proportion of the firm granted to the manager as compensation. The time horizon of the shareholders matches the time horizon of the manager, and the time at which the compensation becomes vested. The value $R$ represents the minimum utility the manager must be able to achieve through the optimal choice of effort and volatility in order to work for the firm. ${ }^{1}$

\section{Optimal strategies}

In this section we derive the solution to the problems of the manager and shareholders as described in the previous section. We will show that the solution to the problem of the manager is essentially dynamic and thus different from the solution to the static version of the problem that we consider in this paper. At the end of this section, we discuss the solution to the static problem. In order to derive analytic solutions, we impose some restrictions. Nevertheless, it appears that the model can provide some robust insights to the main problem addressed in this paper, namely, the optimal leverage of the firm when the principal is less risk-averse than the agent and the agent can choose both the effort and the volatility of the firm.

In particular, there are two assumptions of our model that determine a subset of our quantitative results, but upon which the intuition of our general conclusions does not seem to depend. First, we constrain the shareholders to grant stock (with some optimal degree of leverage) as the single source of compensation to the manager; i.e., we do not allow other types of payments to the manager, like cash, for example. Second, the utility of the manager is logarithmic (any utility of the CRRA class would yield similar qualitative results). With these two assumptions, it will always be optimal for the manager to apply a level of effort that is at least sufficient to guarantee that the stock will have a positive value and the firm will avoid bankruptcy at the end of the horizon considered, as discussed in footnote 1. However, the utility of the manager depends heavily on the level of effort, so, given the participation constraint, high leverage will be suboptimal for many parameter values. In this setting, the optimal contract with no restriction in the type of compensation would consist of a fixed amount of cash that would match the reservation utility $R$ plus an infinitesimal amount of stock; in this case, the manager would choose $v=\infty$, which would guarantee an infinite expected value of the firm. Since shareholders are riskneutral, they do not care about the volatility of the value of the firm. This unrealistic

\footnotetext{
${ }^{1}$ We assume that in case of bankruptcy the payoff to the shareholders is zero and, as we explain later, for $\delta>0$, default never occurs. However, in practice, deviations from absolute priority take place in bankruptcy (see e.g. Franks and Torous, 1989). If shareholders expect to have a positive payoff in default, it might be optimal for the manager to allow the firm to default. The payoff (minus possible bankruptcy costs) would have to be an argument of equations (5) and (6). Unfortunately, that problem does not have a closed-form solution, and there does not exist a clear tractable numerical algorithm to solve it.
} 
result arises because of the combination of risk-neutral shareholders and unbounded volatility. We point out that this result would also obtain in a static setting. Ideally, we would have risk-averse shareholders (same type of utility as the manager, but less risk-aversion) and some type of boundary for volatility. Unfortunately, an explicit solution to that problem does not appear feasible, neither in a static nor dynamic setting. While the restricted setting we consider in this paper prevents the optimality of infinite volatility, shareholders can provide the manager with incentives to choose a sufficiently high level of volatility. We now derive the optimal strategies. Note that the dynamic setting is essential for our results, as we explain later.

Finally, we stress the importance of the fact that the manager cannot diversify the risk resulting from the firm's value. The choice of optimal effort and volatility depends directly on that detail. If the manager did have the possibility to diversify some of this risk, then the optimal effort and volatility would be less sensitive to the level of leverage $B$ chosen by the shareholder, and the manager would be able to undo the effect of leverage by trading other securities.

\subsection{Optimal effort and volatility}

We will present the optimal effort $\hat{u}$ and the optimal choice of volatility $\hat{v}$ of the manager. First we introduce the auxiliary exponential martingale $Z$,

$$
Z_{t}=\exp \left\{-\frac{1}{2} \alpha^{2} t-\alpha W_{t}\right\}
$$

where $\alpha$ is the parameter in (2) that represents the tradeoff between the volatility and expected return of the projects available to the manager. Also, consider the following function of time $\bar{T}$,

$$
\bar{T}_{t}= \begin{cases}\frac{e^{-2 \mu t}\left[e^{\left(\alpha^{2}-2 \mu\right)(T-t)}-1\right]}{\alpha^{2}-2 \mu} & \text { if } \alpha^{2} \neq 2 \mu \\ e^{-\alpha^{2} t}(T-t) & \text { if } \alpha^{2}=2 \mu\end{cases}
$$

Using the previous notation and given the following quadratic equation in $z$,

$$
\delta^{2} \bar{T}_{0} z^{2}+\left(V_{0}-B e^{-\mu T}\right) z-1=0,
$$

where $\delta$ is the parameter that measures the type of the manager and $B$ is the level of debt of the company, we denote by $\check{z}$ the constant positive solution (the Lagrange multiplier) of (10):

$$
\check{z}=\frac{1}{2 \delta^{2} \bar{T}_{0}}\left\{\left(B e^{-\mu T}-V_{0}\right)+\sqrt{\left(B e^{-\mu T}-V_{0}\right)^{2}+4 \delta^{2} \bar{T}_{0}}\right\} .
$$

We now solve for the optimal controls of the manager. 
Theorem 1 Consider the problem of the manager described in Section 2.2. Consider also the exponential martingale of (8), the time function $\bar{T}$ of (9), and the positive number $\check{z}$ of (11). Assume $\delta>0$. Then, the optimal effort $\hat{u}$ of the manager is

$$
\hat{u}_{t}=\delta \check{z} e^{-\mu t} Z_{t}
$$

and the optimal choice of volatility $\hat{v}$ is given by

$$
\hat{v}_{t} V_{t}=\frac{\alpha e^{\mu t}}{\check{z} Z_{t}}+\alpha \check{z} \delta^{2} e^{\mu t} Z_{t} \bar{T}_{t} .
$$

The optimal effort and volatility together determine that the value of the firm be given by

$$
V_{t}=\frac{e^{\mu t}}{\check{z} Z_{t}}+B e^{-\mu(T-t)}-\check{z} \delta^{2} e^{\mu t} Z_{t} \bar{T}_{t} .
$$

If $V_{0}>B e^{-\mu T}$, the above formulas remain valid even for $\delta=0$, but with

$$
\check{z}=\frac{1}{V_{0}-B e^{-\mu T}} .
$$

If $V_{0}<B e^{-\mu T}$ and $\delta=0$, then the utility of the manager is negative infinity since it is impossible in this case to guarantee $V_{T}>B$ with probability one.

Proof. See the Appendix.

Remark 1 When $\delta>0$, equation (14) with $t=T$ indicates that the manager applies enough effort to guarantee that $V_{T}>B$ with probability one, otherwise expected utility is negative infinity. Therefore, bankruptcy never occurs. When $\delta=0$ and $V_{0}>$ $B e^{-\mu T}$, the manager still can (and will) avoid bankruptcy by choosing the appropriate volatility. However, when $\delta=0$ and $V_{0} \leq B e^{-\mu T}$, the manager cannot guarantee $V_{T}>B$ with probability one, and the problem does not have a solution.

We observe that the optimal levels of effort and volatility can also be written as functions of the value of the firm. That is, when $\delta>0$,

$$
\hat{u}_{t}=\frac{e^{-2 \mu t}}{2 \delta \bar{T}_{t}}\left\{\left(B e^{-\mu(T-t)}-V_{t}\right)+\sqrt{\left(B e^{-\mu(T-t)}-V_{t}\right)^{2}+4 \delta^{2} e^{2 \mu t} \bar{T}_{t}}\right\}
$$

and

$$
\begin{aligned}
\hat{v}_{t} V_{t}= & \frac{\alpha \delta}{\hat{u}_{t}}+\alpha \delta e^{2 \mu t} \hat{u}_{t} \bar{T}_{t} \\
= & \frac{2 \alpha \delta^{2} \bar{T}_{t} e^{2 \mu t}}{\left(B e^{-\mu(T-t)}-V_{t}\right)+\sqrt{\left(B e^{-\mu(T-t)}-V_{t}\right)^{2}+4 \delta^{2} e^{2 \mu t} \bar{T}_{t}}} \\
& +\frac{\alpha}{2}\left[\left(B e^{-\mu(T-t)}-V_{t}\right)+\sqrt{\left(B e^{-\mu(T-t)}-V_{t}\right)^{2}+4 \delta^{2} e^{2 \mu t} \bar{T}_{t}}\right] .
\end{aligned}
$$


In Table 1 we study the effect of different parameter values on optimal effort. First, we observe that $\hat{u}$ is increasing in the level of debt $B$. This effect is different from the asset substitution effect of Jensen and Meckling (1976); here the manager is risk-averse and the stock of a levered firm is the single source of compensation and utility to the manager. The higher the leverage, the higher the impact of the effort on the value of the compensation, since the manager receives more shares of a levered firm than an unlevered firm. Leverage increases the incentives of the manager, which is consistent with the findings of Hall and Murphy (2000, 2002). In Section 4 we elaborate further on this point. Also, the longer the time horizon, the lower the effort of the manager. The intuition is clear: a larger $T$ has a similar effect on the manager as a lower level of debt. The effect of $\delta$, the "type" of manager, depends on the relationship between $V_{t}$ and $B$. When $V_{t}=B$, the optimal effort is independent of $\delta$, as we can see from (16). We can also verify that when $V_{t}>B$, the effort is increasing in $\delta$, and when $V_{t}<B$, the optimal effort decreases with $\delta$. The fact that the relationship changes for $V_{t}=B$ is due to the logarithmic utility function and the absence of cash compensation. CRRA utility forces the manager to drive the value of the firm above the debt level. When $V_{t} \geq B$, the main risk (default) is greatly lowered, and thus the higher the marginal productivity of effort, the higher the effort exercised by the manager. The effect of $\mu$, the exogenous component of the drift that does not depend on the effort of the manager, is straightforward: the higher this component, the lower the effort of the manager. In a favorable economic environment the manager has to apply less effort than in difficult circumstances. Finally, the effect of $\alpha$ is also unambiguous: the higher $\alpha$, the lower the optimal effort, or, the better the menu of projects from which the manager can choose, the lower the effort.

We study the dependence of volatility on the different parameter values in Table 2. For $\delta>0$, as in Carpenter (2000), high volatility might not be optimal (it is always optimal in the risk-neutral setting of John and John, 1993). The relationship between volatility $v_{o} V_{0}$ and leverage $B$ is not monotonic: $v_{0} V_{0}$ is a decreasing function of $B$ when $B \in\left[0, V_{0}\right]$, and is an increasing function when $B \in\left(V_{0}, \infty\right)$. The intuition of this result is as before. When the value of the firm is higher than the nominal level of debt, then the higher the leverage, the higher the volatility chosen by the manager. When the level of debt is higher than the value of the firm and, therefore, the payoff of the manager would be zero if debt expired, the manager chooses lower volatility and relies more on effort to ensure there is no default. Similarly, the relationship between volatility and the exogenous component of the drift $\mu$ is also nonlinear. Rather, this relation depends on the leverage ratio and the horizon. For a long horizon, optimal volatility is always increasing in $\mu$. In the short horizon, it increases with $\mu$ if the level of debt is lower than the value of the company, but decreases with $\mu$ when $B>V$. We also see that the volatility is increasing in the type of manager $\delta$. Finally, as expected, the level of volatility increases with $\alpha$.

It is also interesting to study the correlation between optimal effort and optimal volatility. By Ito's Lemma and equation (13), the dynamics of the optimal volatility 
are

$$
d\left(\hat{v}_{t} V_{t}\right)=(\cdot) d t+\alpha^{2}\left(\frac{e^{\mu t}}{\check{z} Z_{t}}-\delta^{2} \check{z} Z_{t} e^{\mu t} \bar{T}_{t}\right) d W_{t} .
$$

Equation (12) yields

$$
d \hat{u}_{t}=(\cdot) d t-\alpha \hat{u}_{t} d W_{t} .
$$

It is clear that the correlation can be either positive or negative. Considering only the instantaneous correlation and ignoring the drift terms, we see that for a short horizon, effort and volatility tend to be negatively correlated and increases in the optimal effort will typically be associated with decreases of the optimal level of volatility. We illustrate this point in Figure 1, where we show a combination of optimal values of the levels of effort and volatility for different states (i.e., different values of $Z$ ).

\subsection{Optimal levels of leverage and number of shares}

We assume that all agents have full information about the parameters that characterize the dynamics of the value of the firm, as well as the preferences of the manager. The objective of the shareholders is given by (7). In order to characterize the optimal choice of $B$ and $n$, we introduce the function

$$
J(z, n)=\frac{e^{\mu T}}{z}\left((\lambda-n) e^{\alpha^{2} T}-\lambda\right)+\lambda z \delta^{2} \bar{T}_{0} e^{\mu T}+\lambda V_{0} e^{\mu T} .
$$

We show in the Appendix that this is the objective function of the firm, using as $\operatorname{arguments} z=\check{z}$ and $n$. We see that the optimal $n$ is the smallest $n$ that shareholders can choose, namely, the smallest $n$ such that the participation constraint of the manager is satisfied. Also in the Appendix, the participation constraint (6) yields

$$
\frac{1}{2} \delta^{2} \bar{T}_{0} z^{2}-\mu T+\log z-\log n-\frac{\alpha^{2}}{2} T+R=0 .
$$

From (21) it follows that the firm will take the value of $n$ equal to

$$
n(z)=z e^{\left\{R-\mu T-\alpha^{2} T / 2+\delta^{2} \bar{T}_{0} z^{2} / 2\right\}} .
$$

Substituting (22) back into $J(z, n)$, the objective function of the firm becomes a function of one argument only; i.e.,

$$
J(z)=\frac{e^{\mu T}}{z} \lambda\left(e^{\alpha^{2} T}-1\right)-e^{\left\{R+\alpha^{2} T / 2+\delta^{2} \bar{T}_{0} z^{2} / 2\right\}}+\lambda z \delta^{2} \bar{T}_{0} e^{\mu T}+\lambda V_{0} e^{\mu T} .
$$

We now introduce some important values of $z$. We define

$$
z_{0}=\frac{-V_{0}+\sqrt{V_{0}^{2}+4 \delta^{2} \bar{T}_{0}}}{2 \delta^{2} \bar{T}_{0}}
$$


which from (10)-(11) we can see that this value corresponds to $B=0$. If $\delta=0$, we recall (10) and define $z_{0}=1 / V_{0}$. Recall from (14) that a given value of $z$ corresponds to the value of $B$ given by

$$
B=e^{\mu T}\left(V_{0}-\frac{1}{z}+z \delta^{2} \bar{T}_{0}\right) .
$$

Denote by $z_{\max }$ the value of $z$ which corresponds to $B=V_{0}$ according to (25).

We denote by $z_{1}<z_{2}<\cdots<z_{L}$ the solutions (if any) to the nonlinear equation

$$
0=J^{\prime}(z)=\frac{\lambda e^{\mu T}}{z^{2}}\left(1-e^{\alpha^{2} T}\right)-z \delta^{2} \bar{T}_{0} e^{\left\{R+\alpha^{2} T / 2+\delta^{2} \bar{T}_{0} z^{2} / 2\right\}}+\lambda \delta^{2} \bar{T}_{0} e^{\mu T}
$$

in the open interval $\left(z_{0}, z_{\max }\right)$. In other words, at these values the derivative of the objective function $J$ of (23) is equal to zero.

We observe that when $\delta=0, J^{\prime}(z) \leq 0$. Furthermore, when $\delta>0, J^{\prime}(\infty)=-\infty$. Hence, for any $\delta \geq 0, J^{\prime}(z)$ cannot be positive for all $z \geq 0$.

We denote by $0=B_{0}, B_{1}, \ldots, B_{L}$ the values of $B$ corresponding to $z_{0}<z_{1}<$ $\cdots<z_{L}$. Since $B$ of $(25)$ is an increasing function of $z$, we see that $0=B_{0}<B_{1}<$ $\cdots<B_{L}<V_{0}$. According to (6), we would like $B \in\left[0, V_{0}\right]$. Thus, $h$ of $(7)$ achieves its maximum at one of the $L+2$ points, $0=B_{0}<B_{1}<\cdots B_{L}<V_{0}$. Equivalently, $J$ of (23) achieves its maximum at one of the $L+2$ points $z_{0}<z_{1}<\cdots<z_{L}<z_{\max }$.

We now state the result about the optimal levels of debt and number of shares.

Theorem 2 Consider the firm whose objective is given by (7). The optimal level of debt and number of shares are given by

$\hat{B}=B(\check{z})=e^{\mu T}\left(V_{0}-\frac{1}{\check{z}}+\check{z} \delta^{2} \bar{T}_{0}\right) \quad$ and $\quad \hat{n}=n(\check{z})=\check{z} e^{\left\{R-\mu T-\alpha^{2} T / 2+\delta^{2} \bar{T}_{0} \check{z}^{2} / 2\right\}}$,

where, $\check{z} \in\left\{z_{0}, z_{1}, \ldots, z_{L}, z_{\max }\right\}$ is characterized by

$$
J(\check{z})=\max \left(J\left(z_{0}\right), J\left(z_{1}\right), \ldots, J\left(z_{L}\right), J\left(z_{\max }\right)\right) .
$$

Proof. See the Appendix.

We perform some numerical exercises in the next section. Here we consider the case $\delta=0$, for which we can easily obtain a solution.

Corollary 1 Suppose that the manager cannot affect the drift independently of the volatility; i.e., $\delta=0$. Then, it is optimal to grant unlevered stock. That is,

$$
\hat{B}=0 \text {. }
$$


Proof. See the Appendix.

\subsection{Solution to the static problem}

The static problem is similar to the problem we have discuss above, but with constant $u$ and $v$. That is, the manager chooses at $t=0$ levels of effort and volatility that stay constant until the end of the horizon. However, given the logarithmic utility, for any leverage $B>0$, the manager can guarantee that the firm will not default only by choosing a level of volatility $v=0$. Thus, the only way in which the shareholders can induce the manager to choose $v>0$ is by granting stock of an unlevered firm. As we have seen in the dynamic version of the problem, the optimal $B$ is in general different from zero. Of course, this solution would not hold for the case in which the manager also receives a cash compensation that is not related to performance. However, an explicit solution of optimal leverage under such a specification does not seem feasible, even in the static version of the problem. A numerical solution is not straightforward either, since the problem of the manager is two-dimensional and the shareholders would have to select from among all possible solutions of the problem of the manager for a grid of values of $B$.

\section{Numerical examples}

In the previous section we derive expressions for the optimal level of debt and number of shares to offer as compensation. As Theorem 2 shows, we need to find $z$ in the nonlinear equation (26) to find the optimal solution. In this section we compute the optimal $z=\check{z}$ numerically, in order to find when it is optimal to grant unlevered or levered stock. The results are reported in Table 3.

We study how different parameters of the model affect whether the shareholders will optimally grant levered or unlevered stock to the manager. We recall the parameters that characterize our model: $\mu$ is the exogenous component of the drift that proxies for the economic environment (high $\mu$ means the value of the firm has positive momentum, regardless of the actions of the manager); $\delta$ measures the type of the manager (higher $\delta$ means a higher type); $R$ is the reservation utility of the manager; $\lambda$ proxies for the size of the firm (in the sense of the market capitalization value of the firm) such that the larger the firm, the lower the dilution resulting from granting stock to the manager and the more the shareholders care about the expected value of the firm; and, $\alpha$ measures the quality of the projects available to the firm (higher $\alpha$ means a better contribution in expected return for each additional unit of risk). We interpret $\alpha$ as an indicator of the type of investment opportunities available to the management of the firm. The effect of the length of the time horizon $T$ is obvious; the longer the horizon, the more time the manager has to exercise effort, 
the more valuable levered stock becomes for the manager, and, therefore, the more likely levered stock is the optimal compensation. Hence, we fix $T$. In practice, $T$ will be related to the vesting period, which thus provides a lower bound. According to Murphy (1999), it varies between 20 and 50 months across industries. It will also be related to the maturity of debt. According to Barclay and Smith (1995), on average, more than half of the value-weighted debt of a large sample of companies between 1974 and 1992 had maturity of five years or more. They show that average maturity increases for larger firms. Given the empirical evidence, $T=5$ seems a reasonable number. The initial value of the firm is 100 .

We need to emphasize that in our analysis, the particular level of debt is not relevant. Rather, the relevant result is whether it is optimal to grant levered or unlevered stock, and how the leverage ratio depends qualitatively on the parameters of the model. It is clear that for a model with additional cash compensation and/or a different utility function (even within the class of CRRA), the optimal leverage will be in general different from our solutions. Moreover, there are two aspects of leverage that we ignore, namely, the tax shield and the risk of default. These would obviously affect the optimal level of debt. Instead, we only focus on whether it is optimal to have some degree of leverage or none at all, from the point of view of the agency aspects of the problem. In fact, given our particular specification of the problem and the fact that it implies no risk of default, we find that the solution is very often either fully unlevered stock or fully debt financed. As we have argued before, even if the firm is fully debt-financed, the value of the stock is not zero because the manager has the power (and the incentives, since stock is the only type of compensation) to drive the value of the firm above the nominal value of debt. In fact, in our setting it would be possible to have debt that exceeds the value of the firm before maturity (including at $t=0$ ), but the utility function of the manager and the effect of effort guarantee that at the maturity of debt, the value of the firm will be larger than the nominal value of debt. In (6) we require the nominal value of debt to be no larger than the initial value of the firm. However, we only impose that restriction at the initial moment, and not throughout the life of the debt. Arguably, taxes push the optimal leverage ratio upwards, and the possibility of default would push it downwards.

First, we state the effect of the type of manager: the leverage ratio is increasing in the type of manager. The intuition, which is confirmed by the effect of the other parameters, is as follows. The risk-neutral shareholders would like the manager to choose more volatility than the manager (who is risk-averse) would in principle prefer. However, a high-type manager that is given stock with high leverage would choose high volatility in order to take advantage of the higher expected return that comes with volatility. This is consistent with the results of Hall and Murphy (2000, 2002). In their problem, the higher the strike price (equivalent to the leverage of our setting), the greater the incentives for the manager. In our problem, the manager can choose effort and volatility. The advantage of volatility is that it is not costly. Thus, given the incentives, the high-type manager is not afraid to receive stock with high leverage and 
choose a high level of volatility. In the event of a bad state, the high-type manager is more efficient at applying effort to drive up the value of the firm. On the other hand, a low-type manager would be reluctant to receive stock with high leverage because this manager is less efficient in applying effort and it would be too costly to drive the firm out of a bad state. The magnifying effect of leverage on incentives found by Hall and Murphy $(2000,2002)$ is not enough for low-type managers to overcome their risk-aversion. This result is in the line of Bertrand and Schoar (2002), who show that some characteristics of the manager (in our model it would be the type) seem to be associated with decisions such as financing.

The exogenous component of the drift $\mu$ has an impact on optimal leverage similar to that of the type of the manager. Intuitively, a favorable economic environment is similar to a high type manager and it is optimal to set a high leverage ratio.

The effect of $R$, the reservation value for the manager, is obvious and unambiguous. A higher reservation value for the manager leads to higher compensation and the optimal way to raise the level of compensation is to lower the leverage.

Next, we turn to the parameter $\lambda$, which we interpret as the size or market capitalization value of the firm. We see that the optimal leverage ratio increases with the emphasis of the shareholders on the value of the firm (a larger firm). This is consistent with the effect of the reservation wage $R$ that we analyze in the previous paragraph.

Finally, we study the effect of changes in $\alpha$. The effect of the projects' quality $\alpha$ is complementary to the effect of $\delta$ : a higher $\alpha$ means a higher expected return as a result of higher volatility. It is clear that higher $\alpha$ will provide more incentives for higher volatility, both to the shareholders and the manager, but more so to the shareholders, because they are risk-neutral. Since leverage makes the stock riskier, a higher $\alpha$ makes a lower leverage ratio optimal, so that the manager is not discouraged from choosing a high level of volatility. This result appears to be consistent with the result of Smith and Watts (1992) who document that firms with better growth prospects tend to have lower leverage. Arguably, $\alpha$ will be higher for firms with a better growth outlook.

In summary, our main results seem to be driven by the interaction of the different risk attitudes of the manager, who is risk-averse, and the shareholders, who are risk-neutral, with the higher risk implicit in levered stock. This is consistent with the empirical findings of Lewellen (2002), who show that managers whose compensation is already levered tend to show reluctance to issue more debt. Our results are also complementary to those in Morellec (2003). We show additional reasons why debt might be low, as is observed in practice. In particular, low-type managers, low momentum, high growth prospects, a high reservation wage (due to competitive pressure to attract managers, for example), and small size will all induce low leverage.

The intuition we derive in our setting with respect to the agency implications of the financing choice seems to be robust to more general settings. For example, if the manager receives a very small amount of cash compensation along with the (levered or 
unlevered) stock, it appears that risk-aversion and leverage of the stock still produce the same qualitative effects.

\section{Conclusions}

In this paper, we consider the incentive effects of levered versus unlevered stock, which is granted by risk-neutral shareholders to a risk-averse manager who can affect the value of the firm through his or her choice of costly effort and non costly volatility of the projects. The objective of the shareholder is to maximize the value of the firm, net of the compensation package. We obtain explicit expressions for the optimal levels of effort and volatility. The higher risk that derives from leverage is at the core of our results. Our main conclusion is that levered stock seems to be the optimal compensation for high-type managers, while unlevered stock is optimal for low-type managers. The intuition is that the risk-neutral shareholders would like the manager to take more aggressive actions than the manager would otherwise prefer. Levered stock provides the correct incentives to good managers, as they will be more willing to take greater risk because their higher ability will enable them to correct a possible bad state through more effort. However, low-type managers will be reluctant to accept the risk that comes with the extra (increase in) leverage, as they are more averse to the possibility that the value of the firm drops rapidly in price. For low-type managers, it follows that unlevered stock will be the preferable type of compensation.

Clearly, our result is essentially dynamic because it relies on the ability of managers to adjust their choices in a dynamic way. In the equivalent static problem, leverage is never optimal because managers would have to choose a level of volatility equal to zero regardless of their type.

\section{Appendix A. Proofs}

\section{A.1. Proof of Theorem 1}

We consider the more general case in which the manager maximizes

$$
\max _{u, v} E\left[F\left(V_{T}\right)-\int_{0}^{T} G\left(u_{s}\right) d s\right]
$$

where

$$
F(s)=\frac{1}{\gamma}\left[n(s-B)^{+}\right]^{\gamma}, \quad G(u)=\frac{u^{2}}{2}
$$

and $\gamma<1$ is the risk-aversion parameter. The log-utility case $F(x)=\log (x)$ corresponds to $\gamma=0$. We approach this problem by familiar duality/martingale techniques, as introduced by Cox and Huang (1989), Karatzas, Lehoczky, and Shreve 
(1987). Consider the dual function

$$
\tilde{F}(z)=\max _{s \geq 0}[F(s)-s z] .
$$

The maximum is attained at the points of the form

$$
\hat{s}=\hat{s}(z, a)=\left(\left(\frac{z}{n^{\gamma}}\right)^{\frac{1}{\gamma-1}}+B\right) \mathbf{1}_{\left\{\left(\frac{z}{n \gamma}\right)^{\frac{1}{\gamma-1}}>\frac{B \gamma}{1-\gamma}\right\}}+a \mathbf{1}_{\left\{\left(\frac{z}{n \gamma}\right)^{\frac{1}{\gamma-1}}=\frac{B \gamma}{1-\gamma}\right\}},
$$

where $a$ is either 0 or $\left(\frac{z}{n^{\gamma}}\right)^{\frac{1}{\gamma-1}}+B$. Consider also the dual function

$$
\tilde{G}(z)=\max _{u}[-G(u)+\delta u z],
$$

where the maximum is attained at

$$
\hat{u}=\hat{u}(z)=\delta z .
$$

Define the stochastic process $\tilde{Z}$ by

$$
\tilde{Z}_{t}=e^{-\mu t} Z_{t}=e^{-\mu t} \exp \left\{-\frac{1}{2} \alpha^{2} t-\alpha W_{t}\right\}
$$

where $Z$ is the exponential martingale defined in (8). Define the stochastic process

$$
M_{t}=\tilde{Z}_{t} V_{t}-\delta \int_{0}^{t} \tilde{Z}_{s} u_{s} d s
$$

Applying Ito's formula, we get

$$
d M_{t}=\left(v_{t}-\alpha\right) V_{t} \tilde{Z}_{t} d W_{t} \quad \text { and } \quad M_{0}=V_{0} .
$$

Obviously, $M$ is a local martingale, but we would like to prove that $M$ is also a martingale. For that purpose, it is sufficient to verify the condition

$$
E\left[\sup _{0 \leq t \leq T}\left|M_{t}\right|\right]<\infty
$$

According to the Burkholder-Davis-Gundy inequality (see, e.g., Theorem 3.3.28 of Karatzas and Shreve, 1991), it is sufficient to verify

$$
E\left[\left(\int_{0}^{T}\left(v_{t}-\alpha\right)^{2} V_{t}^{2} \tilde{Z}_{t}^{2} d t\right)^{1 / 2}\right]<\infty .
$$

We observe that, according to Theorem 1.6.16 of Yong and Zhou (1999), $E\left[\sup _{0 \leq t \leq T} \tilde{Z}_{t}^{2}\right]<$ $\infty$. Since $E\left[\int_{0}^{T}\left|v_{t} V_{t}\right|^{2} d t\right]<\infty$, that theorem, applied to equation (2), gives $E\left[\sup _{0 \leq t \leq T} V_{t}^{2}\right]<$ 
. Applying Hölder's inequality (see, e.g., Theorem 4.2 of Chow and Teicher, 1988) and again the condition $E\left[\int_{0}^{T}\left|v_{t} V_{t}\right|^{2} d t\right]<\infty$, we note that

$$
\begin{aligned}
E\left[\left(\int_{0}^{T}\left(v_{t} V_{t} \tilde{Z}_{t}\right)^{2} d t\right)^{1 / 2}\right] & \leq E\left[\left(\sup _{0 \leq t \leq T} \tilde{Z}_{t}^{2} \int_{0}^{T}\left(v_{t} V_{t}\right)^{2} d t\right)^{1 / 2}\right] \\
& =E\left[\left(\sup _{0 \leq t \leq T} \tilde{Z}_{t}^{2}\right)^{1 / 2}\left(\int_{0}^{T}\left(v_{t} V_{t}\right)^{2} d t\right)^{1 / 2}\right] \\
& \leq\left(E\left[\sup _{0 \leq t \leq T} \tilde{Z}_{t}^{2}\right]\right)^{1 / 2}\left(E\left[\int_{0}^{T}\left(v_{t} V_{t}\right)^{2} d t\right]\right)^{1 / 2} \\
& <\infty .
\end{aligned}
$$

This implies that

$$
E\left[\left(\int_{0}^{T}\left(\left(v_{t}-\alpha\right) V_{t} \tilde{Z}_{t}\right)^{2} d t\right)^{1 / 2}\right]<\infty
$$

and therefore $M$ is a martingale. Thus,

$$
E\left[M_{T}\right]=E\left[M_{0}\right]=V_{0}
$$

By definitions, we get

$$
E\left[F\left(V_{T}\right)-\int_{0}^{T} G\left(u_{s}\right) d s\right] \leq E\left[\tilde{F}\left(z \tilde{Z}_{T}\right)+\int_{0}^{T} \tilde{G}\left(z \tilde{Z}_{s}\right) d s\right]+z E\left[M_{T}\right]
$$

where we can replace $E\left[M_{T}\right]$ by $V_{0}$. Therefore, the above inequality gives an upper bound for our maximization problem. The upper bound will be attained if the maximums are attained and if $E\left[M_{T}\right]=V_{0}$. In other words, the optimal terminal value of the firm and the optimal effort $\hat{u}$ are given by

$$
V_{T}=\hat{s}\left(\check{z} \tilde{Z}_{T}, A\right) \quad \text { and } \quad \hat{u}_{t}=\delta \check{z} \tilde{Z}_{t}
$$

where $A$ and $\check{z}$ are chosen such that $A$ is any $\mathcal{F}_{T}$ measurable random variable which takes only two possible values, 0 and $\left(\frac{\check{z} \tilde{Z}_{T}}{n \gamma}\right)^{\frac{1}{\gamma-1}}+B$, and such that $E\left[M_{T}\right]=V_{0}$.

For $\gamma=0$, we can choose $A \equiv 0$, and we see that

$$
V_{T}=\frac{1}{\check{z} \tilde{Z}_{T}}+B \text {. }
$$

Using this and the martingale property of $M$, we get

$$
\tilde{Z}_{t} V_{t}-\delta \int_{0}^{t} \tilde{Z}_{s} u_{s} d s=E\left[\tilde{Z}_{T} V_{T}-\delta \int_{0}^{T} \tilde{Z}_{s} u_{s} d s \mid \mathcal{F}_{t}\right]
$$


or equivalently

$$
\tilde{Z}_{t} V_{t}=E\left[\frac{1}{\check{z}}+B \tilde{Z}_{T}-\check{z} \delta^{2} \int_{t}^{T} \tilde{Z}_{s}^{2} d s \mid \mathcal{F}_{t}\right]=\frac{1}{\check{z}}+B e^{-\mu T} Z_{t}-\check{z} \delta^{2} Z_{t}^{2} \bar{T}_{t},
$$

in the notation of (9). In other words,

$$
V_{t}=\frac{e^{\mu t}}{\check{z} Z_{t}}+B e^{-\mu(T-t)}-\check{z} \delta^{2} e^{\mu t} Z_{t} \bar{T}_{t}
$$

Using Ito's Lemma, we see that the diffusion term of $V$ is given by

$$
\hat{v}_{t} V_{t}=\frac{\alpha e^{\mu t}}{\check{z} Z_{t}}+\alpha \check{z} \delta^{2} e^{\mu t} Z_{t} \bar{T}_{t}
$$

as claimed in (13). We observe that $\hat{u}$ and $\hat{v}$ defined above are adapted stochastic processes with $E\left[\int_{0}^{T}\left|\hat{u}_{t}\right|^{2} d t\right]<\infty$ and $E\left[\int_{0}^{T}\left|\hat{v}_{t} V_{t}\right|^{2} d t\right]<\infty$. Finally, the requirement $E\left[M_{T}\right]=V_{0}$, which is obtained by setting $t=0$ in (47), gives

$$
V_{0}=\frac{1}{\check{z}}+B e^{-\mu T}-\check{z} \delta^{2} \bar{T}_{0} .
$$

This is equivalent to (10).

\section{A.2. Proof of Theorem 2}

Our first objective is to compute the objective function of the shareholders

$$
h(B, n):=\lambda E\left[V_{T}\right]-n E\left[\left(V_{T}-B\right)^{+}\right],
$$

and

$$
e=e(n, B):=\max _{u, v} E\left[\log \left\{n\left(V_{T}-B\right)^{+}\right\}-\frac{1}{2} \int_{0}^{T} u_{t}^{2} d t\right] .
$$

It is easily seen that

$$
E\left[Z^{2}(t)\right]=e^{\alpha^{2} t}, \quad E[Z(t)]=1, \quad \text { and } E\left[Z^{-1}(t)\right]=e^{\alpha^{2} t} .
$$

Thus, according to equation (14),

$$
E\left[V_{t}\right]=\frac{e^{\mu t}}{\check{z}} e^{\alpha^{2} t}+B e^{-\mu(T-t)}-\check{z} \delta^{2} e^{\mu t} \bar{T}_{t} .
$$

We also see that

$$
E\left[\left(V_{T}-B\right)^{+}\right]=\frac{e^{\mu T}}{\check{z}} e^{\alpha^{2} T},
$$


and, using (25), we can verify that the value $h(B, n)$ of $(50)$ is equal to the value $J(z, n)$ of (20). Again using (25), we see that, indeed, the value $z_{0}$ of (24) corresponds to $B=0$. Finally, using $\hat{u}_{t}=\delta \check{z} e^{-\mu t} Z_{t}$ and (52), we can compute

$$
e=\log (n / z)+\mu T+\frac{\alpha^{2}}{2} T-\frac{1}{2} \delta^{2} \check{z}^{2} \bar{T}_{0}
$$

in terms of $z$ and $n$, and we can check that $e(n(z))=R$, with $n(z)$ given by (22).

Now, the shareholders wish to maximize the function $h$ as a function of $B$, so that the level of debt is smaller than or equal to the value of the firm (that is, $\left.B \leq V_{0}\right)$, and the managers's participation constraint is satisfied. Obviously, the function $h$ can only attain a maximum on this interval at one of the $L+2$ points $B_{0}=0<B_{1}<B_{2}<\ldots<B_{L}<V_{0}$.

\section{A.3. Proof of Corollary 1}

In the case $\delta=0$, the objective function of the shareholders is

$$
J(z)=\frac{e^{\mu T}}{z} \lambda\left(e^{\alpha^{2} T}-1\right)-e^{\left\{R+\alpha^{2} T / 2\right\}}+\lambda V_{0} e^{\mu T} .
$$

This is decreasing in $z$ since $e^{\alpha^{2} T}>1$. Thus, it is optimal to take the smallest possible $z, z=z_{0}$, which corresponds to $\hat{B}=0$.

\section{References}

Barclay, M., Smith, C., 1995. The maturity structure of corporate debt. Journal of Finance 50, 609-631.

Bertrand, M., Schoar, A., 2002. Managing with style: The effect of managers on firm policies. Unpublished working paper. University of Chicago.

Black, F., Scholes, M., 1973. The pricing of options and corporate liabilities. Journal of Political Economy 3, 637-654.

Bolton, P., Harris, C., 2001. The continuous-time principal-agent problem: Frequentmonitoring contracts. Unpublished working paper. Princeton University.

Carpenter, J., 2000. Does option compensation increase managerial risk appetite? Journal of Finance 55, 2311-2331.

Chow, Y., Teicher, H., 1988. Probability Theory: Independence, Interchangeability, Martingales. Second Edition. Springer-Verlag, New York.

Cox, J., Huang, C.-F., 1989. Optimal consumption and portfolio policies when asset prices follow a diffusion process. Journal of Economic Theory 49, 33-83. 
Franks, J., Torous, W., 1989. An empirical investigation of US firms in reorganization. Journal of Finance 44, 747-769.

Hall, B., Murphy, K. J., 2000. Optimal exercise prices for executive stock options. American Economic Review 2, 209-214.

Hall, B., Murphy, K. J., 2002. Stock options for undiversified executives. Journal of Accounting and Economics 33, 3-42.

Holmstrom, B., Milgrom, P., 1987. Aggregation and linearity in the provision of intertemporal incentives. Econometrica 55, 303-328.

Jensen, M., Meckling, W., 1976. Theory of the firm: Managerial behavior, agency costs and ownership structure. Journal of Financial Economics 3, 305-360.

Jensen, M., Murphy, K. J., 1990. Performance pay and top-management incentives. Journal of Political Economy 98, 225-264.

Jin, L., 2002. CEO compensation, diversification and incentives. Journal of Financial Economics 66, 29-63.

John, T., John, K., 1993. Top management compensation and capital structure. Journal of Finance 48, 949-974.

Karatzas, I., Lehoczky, J., Shreve, S., 1987. Optimal portfolio and consumption decisions for a 'small investor' on a finite horizon. SIAM Journal of Control and Optimization $25,1557-1586$.

Karatzas, I., Shreve, S., 1991. Brownian Motion and Stochastic Calculus. Second edition. Springer-Verlag, New York.

Kraus, A., Litzenberger, R., 1973. A state-preference model of optimal financial leverage. Journal of Finance 28, 911-922.

Lewellen, K., 2002. Financing decisions when managers are risk averse. Unpublished working paper. University of Rochester.

Merton, R., 1974. On the pricing of corporate debt: The risk structure of corporate debt. Journal of Finance 29, 449-470.

Modigliani, F., Miller, M., 1958. The cost of capital, corporation finance, and the theory of investment. American Economic Review 48, 261-297.

Modigliani, F., Miller, M., 1963. Corporation income taxes and the cost of capital: A correction. American Economic Review 53, 433-443.

Morellec, E., 2003. Can managerial discretion explain observed leverage ratios? Review of Financial Studies. Forthcoming.

Morellec, E., Smith, C., 2003. Investment policy, financial policies, and the control of agency conflicts. Unpublished working paper. University of Rochester.

Murphy, K. J., 1999. Executive compensation. In: Ashenfelter, O., Card, D. (Eds.), Handbook of Labor Economics, Vol. III. North Holland, Amsterdam, pp. 2485-2563.

Ou-Yang, H., 2003. Optimal contracts in a continuous-time delegated portfolio management problem. Review of Financial Studies 16, 173-208.

Schättler, H., Sung, J., 1993. The first-order approach to the continuous-time principalagent problem with exponential utility. Journal of Economic Theory 61, 331-371.

Smith, C., Watts, R., 1992. The investment opportunity set, and corporate financing, dividend, and compensation policies. Journal of Financial Economics 32, 262-292.

Stulz, R., 1990. Managerial discretion and optimal financial policies. Journal of Financial Economics 26, 3-27. 
Sung, J., 1995. Linearity with project selection and controllable diffusion rate in continuoustime principal-agent problems. RAND Journal of Economics 26, 720-743.

Yong, J., Zhou, X. Y., 1999. Stochastic Controls: Hamiltonian Systems and HJB Equations. Springer-Verlag, New York. 


\section{Table 1}

\section{Optimal initial effort}

The column $\hat{u}_{0}$ measures the optimal initial effort at the initial time, for a fixed initial firm value of $V_{0}=100$. In this table, $B$ represents the nominal value of debt, $T$ is the time horizon, $\alpha$ is the parameter that measures the additional expected return resulting from an additional unit of volatility, $\mu$ is the momentum of the firm's value, and $\delta$ is the type of the manager.

\begin{tabular}{|c|c|c|c|c|c|c|c|c|}
\hline & \multicolumn{4}{|c|}{$B=30$} & \multicolumn{4}{|c|}{$B=80$} \\
\hline & $\alpha$ & $\mu$ & $\delta$ & $\hat{u}_{0}$ & $\alpha$ & $\mu$ & $\delta$ & $\hat{u}_{0}$ \\
\hline \multirow[t]{8}{*}{$T=1$} & 0.03 & 0.04 & 5 & 0.067176387 & 0.03 & 0.04 & 5 & 0.199062451 \\
\hline & 0.05 & 0.04 & 5 & 0.067176139 & 0.05 & 0.04 & 5 & 0.199056219 \\
\hline & 0.03 & 0.05 & 5 & 0.066246554 & 0.03 & 0.05 & 5 & 0.191324268 \\
\hline & 0.05 & 0.05 & 5 & 0.066246314 & 0.05 & 0.05 & 5 & 0.191318683 \\
\hline & 0.03 & 0.04 & 6 & 0.080446412 & 0.03 & 0.04 & 6 & 0.234845616 \\
\hline & 0.05 & 0.04 & 6 & 0.080445986 & 0.05 & 0.04 & 6 & 0.234835540 \\
\hline & 0.03 & 0.05 & 6 & 0.079335738 & 0.03 & 0.05 & 6 & 0.225958112 \\
\hline & 0.05 & 0.05 & 6 & 0.079335327 & 0.05 & 0.05 & 6 & 0.225949045 \\
\hline \multirow[t]{8}{*}{$T=5$} & 0.03 & 0.04 & 5 & 0.053314811 & 0.03 & 0.04 & 5 & 0.109833269 \\
\hline & 0.05 & 0.04 & 5 & 0.053311374 & 0.05 & 0.04 & 5 & 0.109804816 \\
\hline & 0.03 & 0.05 & 5 & 0.049986377 & 0.03 & 0.05 & 5 & 0.096984133 \\
\hline & 0.05 & 0.05 & 5 & 0.049983437 & 0.05 & 0.05 & 5 & 0.096963574 \\
\hline & 0.03 & 0.04 & 6 & 0.063500440 & 0.03 & 0.04 & 6 & 0.128008125 \\
\hline & 0.05 & 0.04 & 6 & 0.063494674 & 0.05 & 0.04 & 6 & 0.127964177 \\
\hline & 0.03 & 0.05 & 6 & 0.059567600 & 0.03 & 0.05 & 6 & 0.113567345 \\
\hline & 0.05 & 0.05 & 6 & 0.143559760 & 0.05 & 0.05 & 6 & 0.113535030 \\
\hline
\end{tabular}


Table 2

\section{Optimal initial volatility}

The column $\hat{v}_{0} V_{0}$ measures the optimal volatility at the initial time, for a fixed initial firm value of $V_{0}=100$. In this table, $B$ represents the nominal value of debt, $T$ is the time horizon, $\alpha$ is the parameter that measures the additional expected return resulting from an additional unit of volatility, $\mu$ is the momentum of the firm's value, and $\delta$ is the type of manager.

\begin{tabular}{|c|c|c|c|c|c|c|c|c|}
\hline & \multicolumn{4}{|c|}{$B=30$} & \multicolumn{4}{|c|}{$B=80$} \\
\hline & $\alpha$ & $\mu$ & $\delta$ & $\hat{v}_{0} V_{0}$ & $\alpha$ & $\mu$ & $\delta$ & $\hat{v}_{0} V_{0}$ \\
\hline \multirow[t]{8}{*}{$T=1$} & 0.03 & 0.04 & 5 & 2.155456748 & 0.03 & 0.04 & 5 & 0.753866538 \\
\hline & 0.05 & 0.04 & 5 & 3.592454339 & 0.05 & 0.04 & 5 & 1.256519782 \\
\hline & 0.03 & 0.05 & 5 & 2.163784566 & 0.03 & 0.05 & 5 & 0.774495997 \\
\hline & 0.05 & 0.05 & 5 & 3.606333588 & 0.05 & 0.05 & 5 & 1.290899234 \\
\hline & 0.03 & 0.04 & 6 & 2.164270802 & 0.03 & 0.04 & 6 & 0.778709874 \\
\hline & 0.05 & 0.04 & 6 & 3.607155901 & 0.05 & 0.04 & 6 & 1.297955113 \\
\hline & 0.03 & 0.05 & 6 & 2.172478933 & 0.03 & 0.05 & 6 & 0.798464221 \\
\hline & 0.05 & 0.05 & 6 & 3.620835478 & 0.05 & 0.05 & 6 & 1.330875068 \\
\hline \multirow[t]{8}{*}{$T=5$} & 0.03 & 0.04 & 5 & 2.343818096 & 0.03 & 0.04 & 5 & 1.201245485 \\
\hline & 0.05 & 0.04 & 5 & 3.906858566 & 0.05 & 0.04 & 5 & 2.003041603 \\
\hline & 0.03 & 0.05 & 5 & 2.374998887 & 0.03 & 0.05 & 5 & 1.278178169 \\
\hline & 0.05 & 0.05 & 5 & 3.958789700 & 0.05 & 0.05 & 5 & 2.131148255 \\
\hline & 0.03 & 0.04 & 6 & 2.378448677 & 0.03 & 0.04 & 6 & 1.267487892 \\
\hline & 0.05 & 0.04 & 6 & 3.964783636 & 0.05 & 0.04 & 6 & 2.113797788 \\
\hline & 0.03 & 0.05 & 6 & 2.407645224 & 0.03 & 0.05 & 6 & 1.337862190 \\
\hline & 0.05 & 0.05 & 6 & 4.013392916 & 0.05 & 0.05 & 6 & 2.230941436 \\
\hline
\end{tabular}


Table 3

\section{Optimal level of debt}

The column $\hat{B}$ measures the optimal level of debt at the initial time for a fixed initial firm value of $V_{0}=100$ and a fixed horizon $T=5$. The column $\hat{n}$ collects the optimal number of shares to offer to the manager as compensation, at the initial time, and for the same initial firm value and time horizon. In this table, $\lambda$ represents the parameter that measures the relative importance of the expected value of the stock with respect to the value of the compensation package, $\alpha$ is the parameter that measures the additional expected return resulting from an additional unit of volatility, $\mu$ is the momentum of the firm's value, $\delta$ is the type of the manager, and $R$ is the reservation compensation of the manager.

\begin{tabular}{|c|c|c|c|c|c|c|c|c|c|c|}
\hline & \multicolumn{5}{|c|}{$\alpha=0.03$} & \multicolumn{5}{|c|}{$\alpha=0.05$} \\
\hline & $\mu$ & $\delta$ & $R$ & $\hat{B}$ & $\hat{n}$ & $\mu$ & $\delta$ & $R$ & $\hat{B}$ & $\hat{n}$ \\
\hline \multirow[t]{8}{*}{$\lambda=5$} & 0.04 & 5 & 5 & 93.827 & 4.819 & 0.04 & 5 & 5 & 91.137 & 4.435 \\
\hline & 0.05 & 5 & 5 & 100 & 4.787 & 0.05 & 5 & 5 & 97.749 & 4.464 \\
\hline & 0.04 & 6 & 5 & 95.150 & 4.863 & 0.04 & 6 & 5 & 93.338 & 4.593 \\
\hline & 0.05 & 6 & 5 & 100 & 4.643 & 0.05 & 6 & 5 & 99.907 & 4.611 \\
\hline & 0.04 & 5 & 6 & 0 & 3.279 & 0.04 & 5 & 6 & 0 & 3.266 \\
\hline & 0.05 & 5 & 6 & 0 & 3.120 & 0.05 & 5 & 6 & 0 & 3.107 \\
\hline & 0.04 & 6 & 6 & 18.572 & 3.847 & 0.04 & 6 & 6 & 0 & 3.258 \\
\hline & 0.05 & 6 & 6 & 28.118 & 3.968 & 0.05 & 6 & 6 & 0 & 3.100 \\
\hline \multirow[t]{8}{*}{$\lambda=6$} & 0.04 & 5 & 5 & 99.649 & 5.836 & 0.04 & 5 & 5 & 98.138 & 5.512 \\
\hline & 0.05 & 5 & 5 & 100 & 4.787 & 0.05 & 5 & 5 & 100 & 4.467 \\
\hline & 0.04 & 6 & 5 & 100 & 5.671 & 0.04 & 6 & 5 & 99.914 & 5.630 \\
\hline & 0.05 & 6 & 5 & 100 & 4.643 & 0.05 & 6 & 5 & 100 & 4.623 \\
\hline & 0.04 & 5 & 6 & 35.834 & 4.617 & 0.04 & 5 & 6 & 0 & 3.266 \\
\hline & 0.05 & 5 & 6 & 44.832 & 4.762 & 0.05 & 5 & 6 & 0 & 3.107 \\
\hline & 0.04 & 6 & 6 & 46.544 & 5.226 & 0.04 & 6 & 6 & 0 & 3.266 \\
\hline & 0.05 & 6 & 6 & 53.640 & 5.277 & 0.05 & 6 & 6 & 0 & 3.107 \\
\hline
\end{tabular}




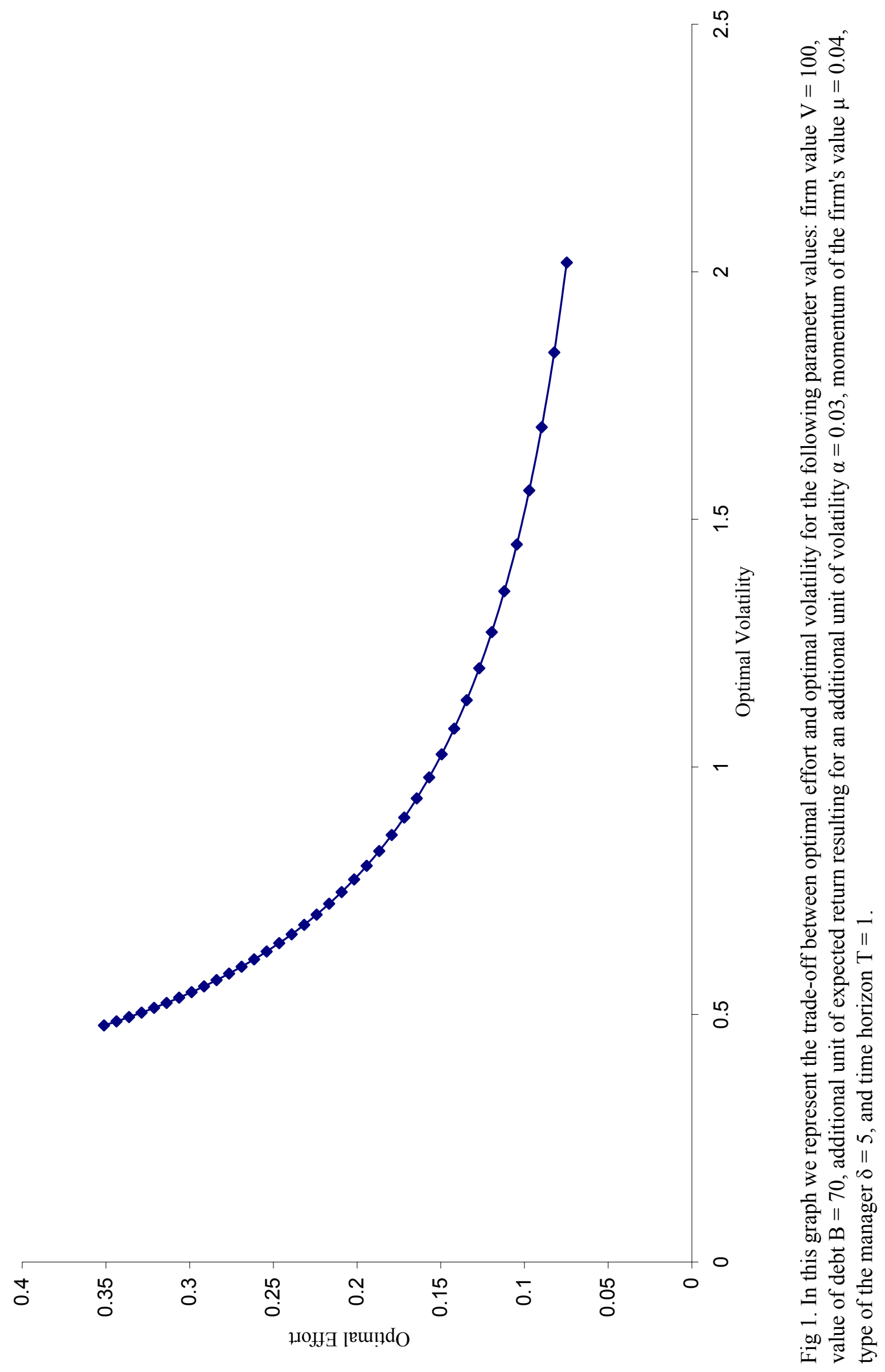

